\title{
THE THERAPEUTIC EFFECT OF OLEANOLIC ACID ON EXPERIMENTALLY INDUCED GASTROESOPHAGEAL REFLUX DISEASE
}

\author{
Eugene Jamot Ndebia ${ }^{1}$, Kiddy Madikizela ${ }^{1}$, Ikanyeng Dolly Seipone ${ }^{1}$, Shauli Mathulo ${ }^{1}$ \\ ${ }^{1}$ Faculty of Health Sciences, Department of Human Biology, Walter Sisulu University, Mthatha - South Africa
}

\begin{abstract}
Objective: This study was aimed to evaluate the therapeutic effect of Oleanolic acid (OA) on experimentally induced Gastroesophageal reflux disease (GERD).

Materials and Methods: GERD was induced in twelve albino Wister rats by daily administration of $2 \mathrm{~mL}$ of acetic acid $15 \%$, $\mathrm{pH}: 2.41$ for 30 days, while another group of three rats received the same volume of distilled water during the same period. The twelve rats being administered acetic acid were divided into four groups of three rats each and treated as follows; Group 1-the control group, with intra-peritoneal administration of $0.2 \mathrm{~mL}$ saline solution; Groups 2 and 3, with intra-peritoneal administration of $0.2 \mathrm{~mL}$ of OA $20 \mathrm{mg} / \mathrm{kg}$ and $40 \mathrm{mg} / \mathrm{kg}$ respectively and Group 4 with oral administration of $2 \mathrm{~mL}$ of Lansoprazole $20 \mathrm{mg} / \mathrm{kg}$. All treatments were given simultaneously with the acetic acid daily for 30 days. All rats' oesophagi were harvested for histological analysis.
\end{abstract}

Results: Rats treated with $20 \mathrm{mg} / \mathrm{kg}$ and $40 \mathrm{mg} / \mathrm{kg}$ OA revealed a more intact oesophageal lining compared to the detached saline group one. There was no damage to blood vessels and the mucosal protective barrier was thick.

Conclusion: Our results suggest that OA may protect the oesophagus against GERD.

Key words: Gastroesophageal reflux disease (GERD), oesophagus, therapy, Oleanolic acid, inflammation.

This article may be cited as: Ndebia EJ, Madikizela K, Seipone ID, Mathulo S. The therapeutic effect of Oleanolic acid on experimentally induced Gastroesophageal Reflux Disease J Med Sci 2021 April;29(2):110-114

\section{INTRODUCTION}

Gastroesophageal reflux disease (GERD) is a common chronic digestive disorder that develops due to the reflux of the acidic stomach contents that cause irritation of the oesophagus lining ${ }^{1,2}$. When gastric contents with $\mathrm{pH}$ range lower than that of the oesophageal $\mathrm{pH} 7.0$ reach the oesophagus, cellular injury, inflammation (acute and chronic) and tissue death can consequently occur ${ }^{3}$. This condition accounts for $75 \%$ of oesophageal diseases worldwide and is estimated to affect up to $33 \%$ of the world's population and the prevalence is reported to be increasing with time ${ }^{4-6}$. GERD is related to everyday lifestyle and has a very costly treatment and management 7,8 . With Africa slowly changing to being urban, there should be expectations of an increase in the disease reports as high-risk factors associated with GERD are the result of urbanization $^{\text {9, } 10}$.

Uncomplicated symptoms of GERD are treated with proton pump inhibitors (PPI) which reduce the acid.

\section{Correspondence}

Dr. Ikanyeng Dolly Seipone

Faculty of Heath Sciences, Walter Sisulu University

Mthatha - South Africa

Email: idseipone@gmail.com

Date received: 18-12-2020

Date revised: 15-01-2021

Date accepted: 01-06-2021
Lack of response from PPI's can result in complications such as; esophagitis, respiratory problems, Barrett's oesophagus, oesophageal strictures and ulcers that might require surgery ${ }^{4,11}$. GERD is a chronic and relapsing condition and these conventional therapies are costly and can be inconvenient. There is a need for data that can provide new treatment insights. Medicinal plants provide therapies that are considered safe and effective compared to the synthetic chemicals and are the main source of structurally important chemical substances that lead to the development of innovative drugs ${ }^{12}$. Plants contain important phytochemicals, one of which is oleanolic acid (OA), a pentacyclic triterpenoid known for its wide array of biological properties ${ }^{13}$. These include anti-nociceptive, anti-cancer, antioxidant and anti-inflammatory properties. ${ }^{14-18} \mathrm{OA}$ is a compound present in food, vegetables and all edible plants ${ }^{19}$. This study was aimed to investigate the therapeutic role of OA in experimentally induced GERD.

\section{MATERIALS AND METHODS}

Albino female Wistar rats weighing $250 \mathrm{~g}$ to 350 $\mathrm{g}$ obtained from the South African vaccine program (Johannesburg, South Africa) were used. They were housed in the Department of Physiology Animal holding facility, Walter Sisulu University (Mthatha, Eastern Cape, South Africa) during the experimental period under standard 
The Therapeutic Effect Of Oleanolic Acid On Experimentally Induced Gastroesophageal Reflux Disease.

light-controlled conditions (12hr light: 12hr dark) and controlled temperature of $24^{\circ} \mathrm{C}$ to $26^{\circ} \mathrm{C}$. These rats were accommodated in groups of 5 animals per cage of 30 $\mathrm{cm}$ (breath) $\times 90 \mathrm{~cm}$ (length) $\times 30 \mathrm{~cm}$ (height). The cage bedding, which was made of wood shaving, was changed twice in 10 days. The animals had access to pellets (EPOL $\mathrm{SA}$ ): protein- $180 \mathrm{~g} / \mathrm{kg}$, moisture- $120 \mathrm{~g} / \mathrm{kg}$, fibre- $60 \mathrm{~g} / \mathrm{kg}$, fat- $60 \mathrm{~g} / \mathrm{kg}$, calcium- $18 \mathrm{~g} / \mathrm{kg}$, phosphorus- $7 \mathrm{~g} / \mathrm{kg}$ ) and water. They were allowed two weeks of acclimatization of the new environment before the start of the experiment. The study was approved by the ethical review committee of Walter Sisulu University under the reference no. 064/2016.

A total of fifteen rats were used. Experimental GERD was induced in twelve rats by daily oral administration of a single dose of $2 \mathrm{~mL}$ of acetic acid $15 \%, \mathrm{pH}: 2.41$ for 30 days. While another group of three rats received the same volume of distilled water during the same period.

The twelve rats were administered a single dose of $2 \mathrm{~mL}$ of acetic acid $15 \%, \mathrm{pH}: 2.41$ were divided into four groups of three rats each and treated as follows; Group 1; the control group was treated with intra-peritoneal administration of $0.2 \mathrm{~mL}$ saline solution. Groups 2 and 3 were treated with intra-peritoneal administration of $0.2 \mathrm{~mL}$ of $\mathrm{OA}$ (SIGMA, St. louis, Missouri, USA) $20 \mathrm{mg} / \mathrm{kg}$ and $40 \mathrm{mg} / \mathrm{kg}$ respectively. Group 4 was treated with oral administration of $2 \mathrm{~mL}$ of Lansoprazole (Cipla, Capetown, SA) $20 \mathrm{mg} / \mathrm{kg}$. All treatments were given simultaneously with the acetic acid daily for 30 days.

At the end of the treatment period, the animals were allowed an overnight fast and, in the morning, they were all sacrificed, and the esophagus was harvested for histological analysis. The oesophagi were kept in $10 \%$ buffered formalin for preservation. Two days after the tissues were preserved, small pieces were cut and routinely processed through ascending grades of alcohol using a TP102 automatic processor and clearing in xylene. The processed oesophagus tissues were then embedded in paraffin wax using embedding unit, trimmed at $30 \mu \mathrm{m}$, and sections cut to a $5 \mu \mathrm{m}$ thickness. Tissue sections were then stained using the Haematoxylin and Eosin technique (Sigma-Aldrich, St Louis Missouri, USA) and mounted for evaluation. The sections were examined using a DMD 108 Imaginer microscope at x10 and x20 magnification.

\section{RESULTS}

The oesophagus of rats that received $2 \mathrm{ml}$ of distilled water for 30 days had intact stratified squamous non-keratinised epithelium overlying loose connective tissue and an intact serosa (Figure $1 \mathrm{~A})$. While all rats that received a daily oral administration of $2 \mathrm{~mL}$ of acetic acid 15 $\%, \mathrm{pH}: 2.41$ during the same period showed a disruption of the squamous epithelial which appeared keratinised and there was thinning of the stratified epithelium. There was also metaplastic mucosal alterations characterised by the detachment of the mucus protective barrier of mucosa of the oesophagus. There was also blood scattered inside the oesophagus indicative of loss of cell cohesion. These histo-morphological changes are indicative of GERD (Figure 1B).

The oesophagus showed no apparent damage on rats given distilled water (H\&E, 10x [A1] and 20x [A2]). [B] Rats treated with acetic acid showed detachment of the mucus protective barrier of mucosa with blood scattered inside the oesophagus and thinning of the stratified epithelium (arrows 1,2 \& 3) (H\&E, 10x [B1] and 20x [B2]), scale bar $=100 \mu \mathrm{m}$.

The oesophagus of the group 1 rats treated with acetic acid and saline only showed keratinised squamous epithelial cells. There was detachment of the mucus protective barrier of mucosa of oesophagus with blood scattered inside the oesophagus and the thinning of the stratified epithelium (Figure 2A). The oesophagus of rats treated with acetic acid and $20 \mathrm{mg} / \mathrm{kg}$ of OA (Group 2) and those given $40 \mathrm{mg} / \mathrm{kg}$ of OA (Group 3) showed an intact stratified squamous keratinised epithelial cells. The granular cell layers were prominent, and the basement membrane was intact (Figure 2B \& $2 \mathrm{C}$ ). Blood vessels with tiny blood spots inside the oesophagus and development and thickening of stratified epithelium and attachment of the mucus protective barrier was more prominent on rats treated with $40 \mathrm{mg} / \mathrm{kg}$ of OA (Figure $2 \mathrm{C}$ ). Rats treated with Lansoprazole (Group 4) showed no irritation with a prominent intact stratified squamous keratinised epithelial cell on their oesophagus (Figure 2D).

Rats treated with saline show detachment of the mucus protective barrier of mucosa and thinning of the epithelium (arrows 1 \& 2). (B.) Oesophagi of rats treated of $20 \mathrm{mg} / \mathrm{kg}$ of OA show an intact mucosa layer in most areas and an intact epithelium (arrow 3). (C.) Oesophagus of rats treated with $40 \mathrm{mg} / \mathrm{kg}$ of OA show a more prominent thick stratified epithelium and attachment of the mucus protective barrier (arrow 4), than that of the $20 \mathrm{mg} / \mathrm{kg}$ of OA rats (D.). Rats treated with Lansoprazole show fully intact and well-developed mucosa and blood vessels. (H\&E, 20x) scale bar $=100 \mu \mathrm{m}$.

\section{DISCUSSION}

The oesophagus is one of the vital organs of the digestive system that serve as a conduit for substances that enter the body through oral cavity ${ }^{20}$. However, highly toxic acidic substances are likely to cause morphological changes in the mucosae of the oesophagus. This study showed detachment of the mucus protective barrier of the mucosae and rupture of the blood vessels after exposure to acetic acid, these histomorphological changes are indicative of gastroesophageal reflux disease (Figure 1B). The absence of the damaged mucosae shown in figure 2 might have been caused by the medicinal ability of OA. 

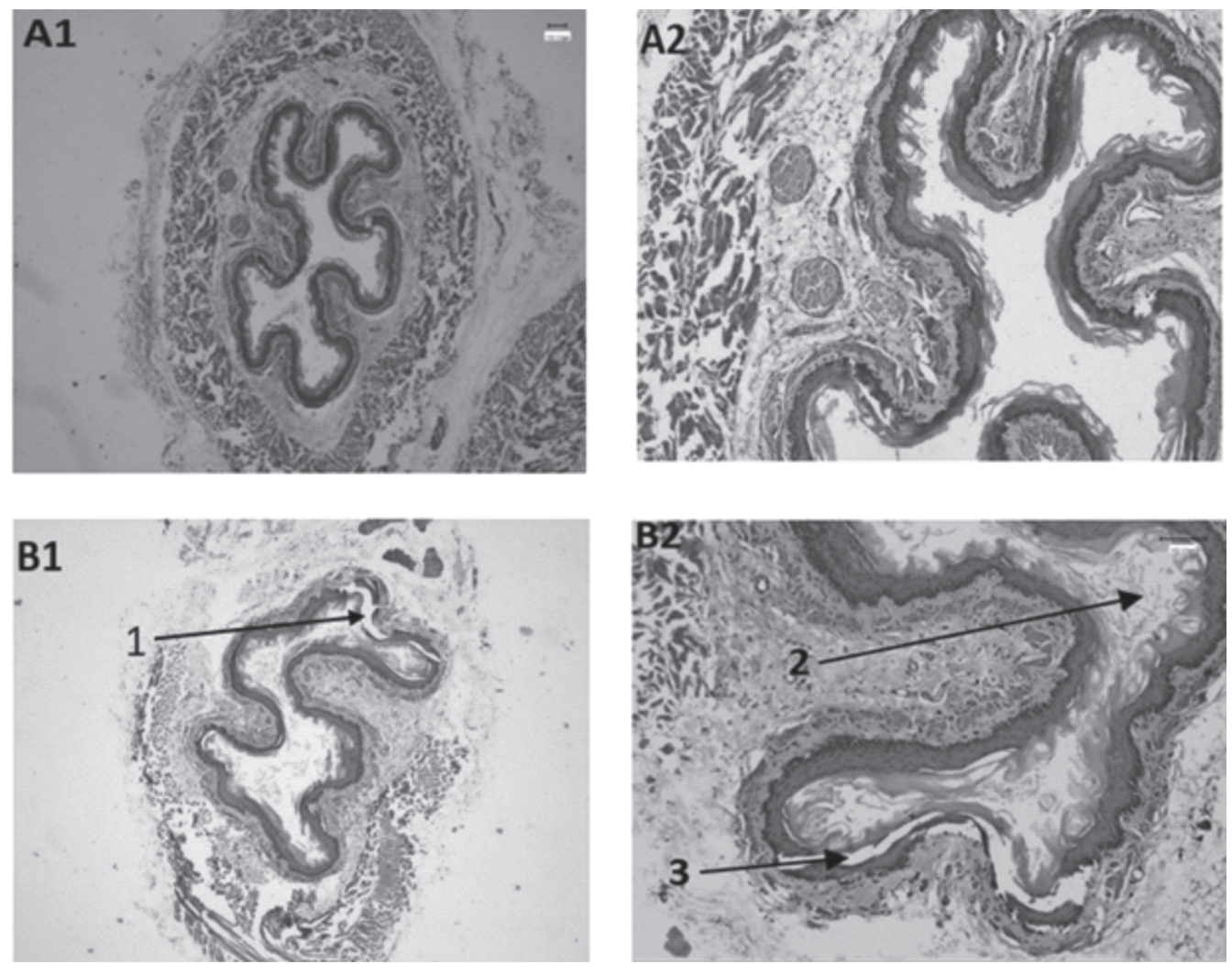

Fig 1: Photomicrographs of the oesophagus of $(A)$ Group 1 rats given distilled water and of (B) group 2 rats given 2 $\mathrm{mL}$ of acetic acid $15 \%$, pH: 2.41 daily for 30 days.
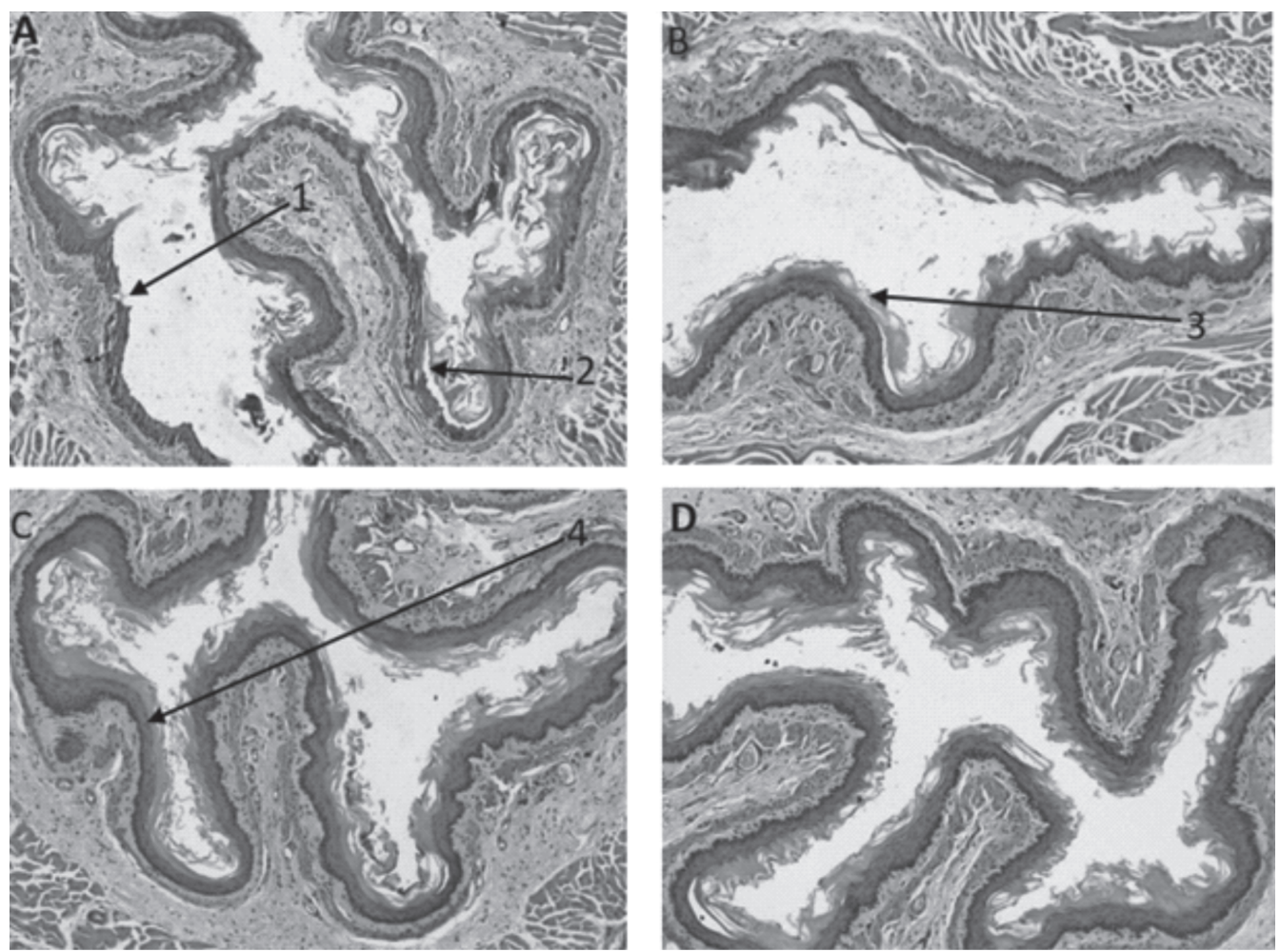

Fig 2: Photomicrographs of the Oesophagus of rats that received (A) $2 \mathrm{~mL}$ of acetic acid 15\%, $\mathrm{pH}: 2.41$ (Group 1) and saline; (B) $0.2 \mathrm{~mL}$ of OA $20 \mathrm{mg} / \mathrm{kg}$ in combination with acetic acid (Group 2); (C) $40 \mathrm{mg} / \mathrm{kg}$ intra-peritoneal in combination with the acetic acid (Group 3); $2 \mathrm{ml}$ Lansoprazole $20 \mathrm{mg} / \mathrm{kg}$ orally in combination with acetic acid (Group 4) for 30 days.. 
The Therapeutic Effect Of Oleanolic Acid On Experimentally Induced Gastroesophageal Reflux Disease.

Previous research have shown OA to be part of phytochemical component of medicinal plants with anti-inflammatory effect. As an example, the anti-inflammatory activities of fruits of Prunus padus, Kleinia odora and Syzygium aromaticum are shown to be due the presence of OA in these plants ${ }^{21-24}$. OA studies have shown that this compound has the ability to reduce oxidative and inflammatory injury through sparing glutathione by raising the activity of superoxide dismutase (SOD) and reducing the release of IL-6 and TNF-a ${ }^{25}$. This compound has been brought into the spotlight of the latest research due to its chemo preventive, anti-inflammatory, antioxidant, hepatoprotective and immunomodulatory properties ${ }^{26}$.

\section{CONCLUSION}

Our results show that OA may have the ability to prevent the effects of the acid secretion, which suggests that the compound may possess anti-inflammatory activity against acetic acid as an aggressive factor of the oesophageal lining as indicated by the prevention of the damage to the lining of the oesophagus. The properties of OA provide advantages to GERD patients by decreasing the aggressive factors and increasing the protective factors showing that plants rich in OA should be used as a good alternative treatment for the disease.

\section{ACKNOWLEDGEMENTS}

We would like to acknowledge Prof. Alastair Sammon for his valuable feedback in the writing of this manuscript.

\section{REFERENCES}

1. Fock KM, Poh CH. Gastroesophageal reflux disease. J. Gastroenterol.2010;45(8):808-15.

2. Patrick L. Gastroesophageal reflux disease (GERD): A review of conventional and alternative treatments. Altern. Med. Rev.2011;16(2):116-33.

3. Keshavarzi Z, Rezapour TM, Vatanchian M, Zare Hesari $\mathrm{M}$, Nabizade Haghighi $\mathrm{H}$, Izanlu $\mathrm{M}$, et al. The effects of aqueous extract of Aloe vera leaves on the gastric acid secretion and brain and intestinal water content following acetic acid- induced gastric ulcer in male rats. Avicenna J phytomedicine 2014;4(2):137-43. Available from: http://www.ncbi.nlm.nih.gov/pubmed/25050311

4. Prakash Gyawali C, Kahrilas PJ, Savarino E, Zerbib F, Mion F, P M Smout AJ, et al. Modern diagnosis of GERD: the Lyon Consensus. Gut 2018;0:1-12. Available from: http://gut.bmj.com/

5. El-Serag HB, Sweet S, Winchester CC, Dent J. Update on the epidemiology of gastro-oesophageal reflux disease: A systematic review. Gut2014;63(6):871-80.

6. WDHD. 150129_WDHD 2015 Message_To Member Societies | Enhanced Reader 2015 Available from: http:// qa.sages.co.za/content/images/WDHD_2015_Heartburn_A_Global_Perspective.pdf
7. Levin TR, Schmittdiel JA, Kunz K, Henning JM, Henke CJ, Colby CJ, et al. Costs of acid-related disorders to a health maintenance organization. Am J Med 1997;103(6):520-8.

8. Peery AF, Dellon ES, Lund J, Crockett SD, McGowan CE, Bulsiewicz WJ, et al. Burden of gastrointestinal disease in the United States: 2012 update. Gastroenterology 2012;143(5).

9. Heath Systems Trust South Africa. (No Title). Durban, South Africa: 2016.

10. Castellano JM, Guinda A, Delgado T, Rada M, Cayuela JA. Biochemical basis of the antidiabetic activity of oleanolic acid and related pentacyclic triterpenes. Diabetes2013;62(6):1791-9.

11. Tack J, Pandolfino JE. Pathophysiology of Gastroesophageal Reflux Disease. Gastroenterology 2018;154(2):27788.

12. Dubey NK, Kumar R, Tripathi P. Global promotion of herbal medicine: India's opportunity. Curr. Sci.2004;86:3741. Available from: https://www.jstor.org/stable/ pdf/24109515.pdf

13. Nkeh-Chungag BN, Oyedeji OO, Oyedeji AO, Ndebia EJ. Anti-Inflammatory and Membrane-Stabilizing Properties of Two Semisynthetic Derivatives of Oleanolic Acid. Inflammation 2014;38(1):61-9.

14. Melo TS, Gattass CR, Soares DC, Cunha MR, Ferreira C, Tavares MT, et al. Oleanolic acid (OA) as an antileishmanial agent: Biological evaluation and in silico mechanistic insights. Parasitol Int.2016;65(3):227-37. Available from: http://www.ncbi.nlm.nih.gov/pubmed/26772973

15. Park SH, Sim YB, Kang YJ, Kim SS, Kim CH, Kim SJ, et al. Mechanisms involved in the antinociceptive effects of orally administered oleanolic acid in the mouse. Arch Pharm Res.2013;36(7):905-11. Available from: http:// www.ncbi.nlm.nih.gov/pubmed/23515934

16. Zhu YY, Huang HY, Wu YL. Anticancer and apoptotic activities of oleanolic acid are mediated through cell cycle arrest and disruption of mitochondrial membrane potential in HepG2 human hepatocellular carcinoma cells. Mol Med Rep 2015;12(4):5012-8.

17. Žiberna L, Šamec D, Mocan A, Nabavi SF, Bishayee A, Farooqi AA, et al. Oleanolic acid alters multiple cell signaling pathways: Implication in cancer prevention and therapy. Int. J. Mol. Sci.2017;18(3).

18. Surh YJ. Cancer chemoprevention with dietary phytochemicals [Internet]. Nat. Rev. Cancer2003;3(10):768-80. Available from: http://www.ncbi.nlm.nih.gov/ pubmed/14570043

19. Li Q, Fan Y-S, Gao Z-Q, Fan K, Liu Z-J. Effect of Ursolic Acid and Oleanolic Acid on Osteoblastic Like Cell-Line MC3T3-E1. Pak Vet J 2015;35(4):414-9. Available from: www.pvj.com.pk

20. Moses BE, Emma EJ, Christopher CM, Enobong I B, Theresa BE. Effect of calabash chalk on the histomorphology of the gastro-oesophageal tract of growing wistar rats. Malays J Med Sci 2012;19(1):30-5. Available from: http://www.ncbi.nlm.nih.gov/pubmed/22977372

21. Kashyap D, Sharma A, S. Tuli H, Punia S, K. Sharma A. Ursolic Acid and Oleanolic Acid: Pentacyclic Terpenoids 
The Therapeutic Effect Of Oleanolic Acid On Experimentally Induced Gastroesophageal Reflux Disease.

with Promising Anti-Inflammatory Activities. Recent Pat Inflamm Allergy Drug Discov 2016;10(1):21-33.

22. Magiera A, Marchelak A, Michel P, Owczarek A, Olszewska MA. Lipophilic extracts from leaves, inflorescences and fruits of Prunus padus $L$. as potential sources of corosolic, ursolic and oleanolic acids with anti-inflammatory activity. Nat Prod Res 2019;1-6.

23. Shehata IA, El-harshany E, Abdallah HM, Esmat A, Abdel-sattar EA. Anti-inflammatory activity of Kleinia odora. Eur J Integr Med 2018;23:64-9.

24. Rali S, Oyedeji OO, Aremu OO, Oyedeji AO, Nkeh-Chungag BN. Semisynthesis of derivatives of oleanolic acid from Syzygium aromaticum and their antinociceptive and anti-inflammatory properties. Mediators Inflamm $2016 ; 2016$

25. Tsai SJ, Yin MC. Anti-oxidative, anti-glycative and anti-apoptotic effects of oleanolic acid in brain of mice treated by d-galactose. Eur J Pharmacol 2012;689(13):81-8. Available from: http://www.ncbi.nlm.nih.gov/ pubmed/22683839

26. Oprean C, Mioc M, Csányi E, Ambrus R, Bojin F, Tatu $\mathrm{C}$, et al. Improvement of ursolic and oleanolic acids' antitumor activity by complexation with hydrophilic cyclodextrins. Biomed Pharmacother 2016;83:1095-104. Available from: https://linkinghub.elsevier.com/retrieve/ pii/S0753332216308599
GRANT SUPPORT AND FINANCIAL DISCLOSURE:

This research was supported by the SA Medical Research Council Self-Initiated Grant (SIG) under Grant number (MRC/SIR-EJ Ndebia) and the NRF Thuthuka under Grant number UID: 107436, ref: TTK160507164324, both awarded to Dr Eugene J. Ndebia.

\section{AUTHOR'S CONTRIBUTION}

Following authors have made substantial contributions to the manuscript as under

Ndebia EJ: Concept, supervision, critical review, data analysis.

Madikizela K: Data collection, critical review.

Seipone ID: Manuscript writing, Critical review.

Mathulo S: Data collection

Authors agree to be accountable for all aspects of the work in ensuring that questions related to the accuracy or integrity of any part of the work are appropriately investigated and resolved. 